\title{
Uso do YouTube no ensino da contabilidade de custos: investigação empírica com alunos do Curso de Ciências Contábeis da Universidade Católica de Brasília
}

\author{
Kelly Cristina de Carvalho Almeida \\ Bacharel em Contabilidade pela Universidade Católica de Brasília \\ QS 07 Lote 01 EPCT, Águas Claras - 71966-700 - Taguatinga/DF \\ Kellynha15@yahoo.com.br \\ Karla Caroline Afiune Simões \\ Bacharel em Contabilidade pela Universidade Católica de Brasília \\ QS 07 Lote 01 EPCT, Águas Claras - 71966-700 - Taguatinga/DF \\ Karlaafiune@gmail.com \\ Idalberto José das Neves Júnior \\ Mestrado em Gestão do Conhecimento e Tecnologia da Informação pela \\ Universidade Católica de Brasília - UCB \\ Professor da Universidade Católica de Brasília - UCB \\ QS 07 Lote 01 - EPCT, Águas Claras, 71966-700 - BRASILIA, DF \\ jneves@ucb.br
}

Esta pesquisa se origina a partir da importância da educação continuada, por meios de novas tecnologias educacionais disponíveis aos interessados pela área contábil. A falta de informação, no que tange ao conhecimento destas tecnologias, possibilitou a busca de ferramentas para o ensino desta ciência que teve início devido a observações despropositadas feitas no site Youtube. O objetivo do trabalho foi investigar a utilização do uso de vídeos postados no YouTube da área contábil para o ensino da contabilidade de custos, e se estes vídeos podem ser considerados como ferramenta educacional. Para tanto, identificou-se os vídeos relacionados à contabilidade de custos, aplicando-se um questionário junto a 21 alunos matriculados na disciplina de contabilidade de custos e 29 alunos matriculados em análise de custos, visando comprovar a utilização do Youtube como mídia educacional. Os principais resultados revelam que na opinião dos alunos o YouTube pode ser considerado como uma nova ferramenta de ensino, sendo capaz de contribuir para o aprendizado de uma pessoa que não possui conhecimento algum sobre o assunto apresentado.

Palavras-chave: Contabilidade de Custos. Ensino-aprendizagem em Custos. Vídeos no Ensino de Custos.

Use of YouTube in the teaching of cost accounting: an empirical research with Accounting students of Universidade Católica de Brasília

This research arose from the importance of continuing education by means of new educational technologies available to interested parties by the accounting department. The lack of information, with regards knowledge of these technologies has enabled the search tool for the teaching of science that started because of the unreasonable comments made on the website Youtube. The objective was to 
Uso do YouTube no ensino da contabilidade de custos: investigação empírica com alunos do Curso de

Ciências Contábeis da Universidade Católica de Brasília

Kelly Cristina de Carvalho Almeida, Karla Caroline Afiune Simões, Idalberto José das Neves Júnior

investigate the use of videos posted on YouTube of the accounting department for the teaching of cost accounting, and if these videos can be considered as an educational tool. To this end, we identified the videos related to cost accounting and received a questionnaire survey of students enrolled in cost accounting courses with 21 students and cost analysis with 29 students for a possible or no evidence of Youtube as a medium education. The main results showed that in the opinion of apprentices YouTube can be considered as a new teaching tool, being able to contribute to the learning of a person who does not have any knowledge about the subject presented.

Keywords: Cost Accounting. Teaching-learning costs. Videos in High Costs.

\section{Introdução}

Nos dias atuais vive-se na era do conhecimento e da tecnologia, logo é necessário que os profissionais estejam constantemente pesquisando e se atualizando sobre os assuntos da sua área de atuação.

De acordo com Cornachione Jr. (2001 apud KRAEMER, 2003, p.26), o ensino da contabilidade passa a contemplar novas realidades, novas potencialidades, derivadas de mídias alternativas, da conectividade que assola a humanidade atualmente, abordando aspectos da tecnologia da informação e seus impactos no ensino e aprendizagem relativos à área de conhecimento contabilidade.

Após o século XVIII a contabilidade de custos passou a ser encarada como uma eficiente forma de auxílio no desempenho da área gerencial, devido ao crescimento das empresas e necessidades dos administradores, tendo duas importantes funções: a de auxiliar no controle, fornecendo dados para estabelecimento de padrões e a ajuda na tomada de decisões, acompanhando o ocorrido com o previsto (MARTINS, 2003).

Apesar da distância física entre professor e aluno, ambos estão interligados tecnologicamente, principalmente por meios telemáticos, como a internet (MORAN, 2009). Bogo (2000) define a Internet como "um conjunto de redes de computadores interligadas que tem em comum um conjunto de protocolos e serviços, de uma forma que os usuários conectados possam usufruir de serviços de informação e comunicação de alcance mundial". 
Uso do YouTube no ensino da contabilidade de custos: investigação empírica com alunos do Curso de

Ciências Contábeis da Universidade Católica de Brasília

Kelly Cristina de Carvalho Almeida, Karla Caroline Afiune Simões, Idalberto José das Neves Júnior

Atualmente o site mais usado para compartilhar vídeos é o YouTube, sem discriminação de qualidade, assunto ou qualquer outra característica. Seu início aconteceu a partir da idéia de dois jovens criativos e ousados, que na garagem de casa em fevereiro de 2005 resolveram criar um site com a finalidade de compartilhar vídeos de autoria própria, pois naquele momento a web não disponibilizava tais recursos $(G 1,2006)$. Esta mídia tecnológica é nova e está em constante atualização, pois a cada momento há novas descobertas e modificações no próprio site.

O objetivo geral do trabalho foi investigar a utilização do uso de vídeos postados no YouTube da área contábil para o ensino da contabilidade de custos. Temos como objetivos específicos, verificar se há contribuição dos vídeos para o aprendizado dos alunos das disciplinas de contabilidade e análise de custos e se estes vídeos podem ser considerados como ferramenta educacional, tendo por base o seguinte problema de pesquisa: Qual a opinião dos alunos do curso de Ciências Contábeis da UCB quanto à utilidade dos vídeos postados no YouTube no processo de ensino-aprendizagem nas disciplinas de custos?

A pesquisa realizada é classificada, segundo Vergara (2000), quanto à sua finalidade em exploratória e descritiva, pois é uma área na qual há pouco conhecimento acumulado e sistematizado além de expor características de determinada população. Quanto ao meio de investigação, trata-se de uma pesquisa de campo desenvolvida por meio de aplicação de questionário endereçado aos alunos da UCB. Os dados foram tabulados no Excel e as análises foram realizadas com o apoio do software Statistical Package for the Social Sciences (SPSS).

O estudo está estruturado em cinco seções. Após a introdução, aborda-se o ensino da contabilidade de custos, a Internet como apoio ao ensino da graduação, técnicas e metodologia de ensino, produção e uso de vídeos para o ensino. A terceira seção trata da metodologia da pesquisa, seguida da análise dos resultados e considerações finais. Por último, são apresentadas as referências.

\section{Revisão da Literatura}

\subsection{Ensino da contabilidade de custos}

A contabilidade de custos vem passando por transformações, sendo que os três principais fatores que possibilitaram esse cenário foram: a revolução industrial, científica e 
Uso do YouTube no ensino da contabilidade de custos: investigação empírica com alunos do Curso de

Ciências Contábeis da Universidade Católica de Brasília

Kelly Cristina de Carvalho Almeida, Karla Caroline Afiune Simões, Idalberto José das Neves Júnior

tecnológica. Com os obstáculos surgidos devido à junção destes acontecimentos, as empresas passaram a buscar novas premissas para obter a informação necessária e a solução destes, visando o aperfeiçoamento do contexto empresarial (RAUPP et al., 2009).

Com os avanços tecnológicos e o mercado globalizado e cada vez mais competitivo, a contabilidade de custos assume um papel cada vez mais importante, pela necessidade da gestão eficiente dos custos, que se configura como uma ferramenta de apoio à gestão das empresas e dos negócios (SCARPIN; GRANDE, 2007).

Diante das mudanças no cenário econômico, no que diz respeito ao conhecimento contábil, a contabilidade de custos tem um papel fundamental na formação de profissionais aptos para exercer a profissão contábil (SCARPIN; GRANDE, 2007).

Scarpin e Grande (2007) constatam que a Contabilidade de Custos, assim como o seu ensino foi se desenvolvendo focada no setor industrial, face à sua origem predominantemente industrial.

\subsection{A Internet como apoio ao ensino da graduação}

Muitos professores ainda se mostram relutantes em aceitar certas mídias, principalmente a Internet, enaltecendo os problemas e desprezando os benefícios gerados. Devido a sua significância no contexto social, a Internet poderá e deverá ser utilizada como uma mídia educacional.

Frente aos desafios modernos, as Instituições de Ensino Superior precisam estar abertas e atuar de forma democrática junto ao seu grupo de docentes. Eles são os responsáveis por tornar a realidade inovadora se fazer presente na vida universitária dos alunos (TOFFOLLI, 2007). As instituições educacionais precisam conhecer as concepções dos estudantes para desenvolver práticas pedagógicas capazes de alcançar resultados positivos para o processo de ensino, introduzindo novas tecnologias e acompanhando essa nova realidade (BRUN; CRUZ, 2002).

A evolução da tecnologia educacional acontece em uma velocidade sempre crescente, então o uso da Internet de maneira consistente se faz urgente em sala de aula para a consolidação do processo de aprendizagem cooperativa e ativa. Anjos e Castro (2010) mencionam que "nos ambientes acadêmicos, o impacto da TI é bastante acentuado em virtude da natureza do trabalho científico, fortemente voltado ao intercâmbio de informações e 
Uso do YouTube no ensino da contabilidade de custos: investigação empírica com alunos do Curso de

Ciências Contábeis da Universidade Católica de Brasília

Kelly Cristina de Carvalho Almeida, Karla Caroline Afiune Simões, Idalberto José das Neves Júnior

experiências entre pesquisadores". Com isso, as instituições de ensino necessitam cada vez mais estar em constante atualização e preparadas para novos desafios.

Não faz muito tempo que a comunicação entre aluno e professor acontecia somente em encontros presenciais. Essa dinâmica sofreu e sofre mudanças atualmente devido a existência da Internet que assume papel eficiente como um canal de comunicação. Ela agrega benefícios geralmente não percebidos por muitos como, por exemplo, o aumento da capacidade de leitura, propicia a procura por informações e resoluções de problemas, preparando os indivíduos para o mercado de trabalho (TOFFOLLI, 2010).

\subsection{Técnicas e metodologias de ensino}

Conforme Nérici et al. (apud MENDES, 2010), a metodologia de ensino convencional é assim apresentada:

\begin{tabular}{|c|c|}
\hline Método & Características \\
\hline Aula Expositiva & $\begin{array}{l}\text { Linguagem oral utilizada pelo professor com o } \\
\text { objetivo de transmitir informações logicamente } \\
\text { estruturadas. }\end{array}$ \\
\hline Seminário & $\begin{array}{l}\text { Levar o aluno a pesquisar sobre determinado tema, } \\
\text { apresentá-lo e discuti-lo cientificamente. }\end{array}$ \\
\hline Excursões ou Visitas & $\begin{array}{l}\text { Visitar a indústria, escritório, bolsa de valores, órgãos } \\
\text { de classes, empresas, associações. }\end{array}$ \\
\hline Dissertações ou resumos & $\begin{array}{l}\text { Buscar obter a interpretação e a avaliação dos } \\
\text { alunos sobre assuntos já tratados ou de forma prévia } \\
\text { daqueles que serão abordados. }\end{array}$ \\
\hline \begin{tabular}{|l} 
Estudo dirigido ou aulas \\
orientadas
\end{tabular} & \begin{tabular}{|llll} 
Orientação aos & alunos quanto ao & estudo \\
aprofundado de determinado conteúdo.
\end{tabular} \\
\hline Jogos de empresas & $\begin{array}{l}\text { Simulação que permite ao aluno aprender em uma } \\
\text { realidade empresarial imitada. }\end{array}$ \\
\hline Estudo de caso & $\begin{array}{l}\text { Apresentar situações ocorridas em empresas com } \\
\text { vistas à sua análise pelos alunos. }\end{array}$ \\
\hline Laboratórios e oficinas & $\begin{array}{l}\text { Aula desenvolvida em laboratórios com a utilização } \\
\text { de softwares Contábeis que permitem a escrituração } \\
\text { e emissão de relatórios. }\end{array}$ \\
\hline Palestra & $\begin{array}{l}\text { Explanação de um profissional da área sobre um } \\
\text { conteúdo aliado a aplicação prática. }\end{array}$ \\
\hline Discussão e debate & $\begin{array}{l}\text { Orientação da classe para que ela mesma realize, } \\
\text { em forma de cooperação intelectual, o estudo da } \\
\text { unidade em foco. }\end{array}$ \\
\hline
\end{tabular}


Uso do YouTube no ensino da contabilidade de custos: investigação empírica com alunos do Curso de

Ciências Contábeis da Universidade Católica de Brasília

Kelly Cristina de Carvalho Almeida, Karla Caroline Afiune Simões, Idalberto José das Neves Júnior

\begin{tabular}{||l|l||}
\hline \hline Resolução de exercícios & $\begin{array}{l}\text { Estudo ativo que proporciona ao aluno aprender com } \\
\text { a prática. }\end{array}$ \\
\hline
\end{tabular}

Quadro 1: Metodologias de Ensino

Fonte: Nérici et al. (apud MENDES, 2010).

Além de conhecer as metodologias de ensino, o professor deverá também compreender os estilos de aprendizagem. Este é entendido como um processo individual de absorção, processamento e retenção de informações (MENDES, 2010). O docente precisa ter 80 domínio do conteúdo especifico concomitantemente com o conhecimento na área pedagógica, pois ao ministrar um conteúdo, a experiência e a sabedoria metodológica são essenciais ao processo sólido e duradouro de aprendizado.

De acordo com Nossa (1999, p.1), no ensino da contabilidade, geralmente, grande parte dos professores é recrutada entre profissionais de sucesso em seu ramo de atuação que, em sua maioria estão despreparados para o magistério, não tendo noção do que é exigido para a formação de seus alunos.

A sociedade sofre transformações em todos os níveis e principalmente na área educacional. O agente responsável por estas alterações é a tecnologia. Adaptar-se a esta realidade é dever de quem educa e para quem aprende, pois a falta desta evolução comportamental tem e terá conseqüências danosas ao ensino no Brasil. Um importante representante deste personagem modificador é a telemática, pois ela disponibiliza ferramentas para a execução da interação do ambiente educacional (NEVES JÚNIOR, et al., 2006).

\subsection{Produções e uso de vídeos para o ensino}

A produção de vídeos digitais de curta duração tornou-se uma atividade muito popular nos dias de hoje. Pode se observar tal sucesso devido à enorme utilização de sites que disponibilizam esses vídeos. Geralmente, eles são produzidos visando o lazer e o entretenimento, mas apesar disso, essa produção pode ser muito utilizada na prática educacional (VARGAS et al., 2007).

Moran (2009a) menciona que "a produção de vídeo no contexto educacional pode ser utilizada como um meio de expressão e de comunicação". O autor constata que a utilização de vídeos está chegando às salas de aula, e com esse recurso os professores conseguem atrair a atenção dos alunos, uma vez que para eles seria uma forma de descanso e não de "aula" (MORAN, 2009b). 
Uso do YouTube no ensino da contabilidade de custos: investigação empírica com alunos do Curso de

Ciências Contábeis da Universidade Católica de Brasília

Kelly Cristina de Carvalho Almeida, Karla Caroline Afiune Simões, Idalberto José das Neves Júnior

É importante que o aluno tenha uma visão de como é realizada a produção de um vídeo para que possa melhorar sempre que precisar e para obter uma autonomia no trabalho produzido (VARGAS et al., 2007). Para Amaral et al. (2006), o uso de vídeos abre portas para a alfabetização audiovisual, permitindo que alunos e professores tenham a capacidade de produzir e analisar suas próprias mensagens, promovendo assim a intervenção social, criando uma educação dinâmica, cooperativa e solidária.

Segundo Amaral et al. (2006), a comunicação do vídeo digital promete ser o meio de comunicação com maior potencialidade deste século, devido à capacidade de ensinar e aprender de forma mais interessante. Falkembach (2005) afirma que "para que um software educativo cumpra sua finalidade é preciso que o professor saiba selecionar e planejar os materiais utilizados em sala de aula, e melhor ainda se ele for capaz de desenvolver seu próprio material".

\section{Metodologia da Pesquisa}

\subsection{Seleção de vídeos no YouTube}

A seleção de vídeos no YouTube foi efetuada no ano de 2010, e definida em três parâmetros: de acordo com a duração de cada vídeo em um intervalo de 0 a 10 minutos, definindo a categoria de pesquisa em "educação", e por fim selecionando os vídeos com as grafias "contabilidade de custos" e "análise de custos".

O próprio site disponibiliza as ferramentas usadas para a formação da variável. Como resultados e de forma a permitir uma melhor identificação do tempo de duração de cada vídeo e sua relação com os resultados da pesquisa, estruturou-se as tabelas a seguir:

Tabela 1: Vídeos com a grafia "Contabilidade de Custos"

\begin{tabular}{lcc}
\hline Duração dos vídeos (Min.) & Quantidade & $\%$ \\
\hline $0-4{ }^{\prime}$ & 18 & $50 \%$ \\
$4-10$ & 16 & $44 \%$ \\
Acima de 10' & 02 & $6 \%$ \\
\hline Total & $\mathbf{3 6}$ & $\mathbf{1 0 0 \%}$ \\
\hline
\end{tabular}

Fonte: Youtube (2010).

Tabela 2: Vídeos com a grafia "Análise de custos"

Duração dos vídeos (Min.) Quantidade \%


Uso do YouTube no ensino da contabilidade de custos: investigação empírica com alunos do Curso de

Ciências Contábeis da Universidade Católica de Brasília

Kelly Cristina de Carvalho Almeida, Karla Caroline Afiune Simões, Idalberto José das Neves Júnior

\begin{tabular}{lcc}
\hline $0-4{ }^{\prime}$ & 37 & $65 \%$ \\
$4-10^{\prime}$ & 18 & $31 \%$ \\
Acima de 10' & 2 & $4 \%$ \\
\hline Total & $\mathbf{5 7}$ & $\mathbf{1 0 0 \%}$ \\
\hline
\end{tabular}

Fonte: Youtube (2010).

Para viabilizar o estudo, optou-se por desenvolver a pesquisa com os vídeos de duração de até 4 minutos, o que correspondeu a 50\% no caso de Contabilidade de custos e $65 \%$ de Análise de custos. A escolha de vídeos de curta duração é justificada dada a necessidade de apresentação desses vídeos aos alunos e coleta da opinião dos mesmos.

Para a qualificação dos vídeos e priorização desses filmes para aplicação da pesquisa, definiram-se os seguintes critérios:

- Identificação dos 15 (quinze) vídeos mais assistidos no Youtube;

- Identificação dos professores especialistas em custos que ministram as disciplinas no Curso de Ciências Contábeis da UCB;

- Exibição dos vídeos para os professores especialistas enumerarem os três mais qualificados pelos quesitos (assertividade de conteúdos, didática, metodologia e qualidade dos vídeos).

\subsection{População e amostra}

A população do estudo estava representada pelos alunos matriculados nas duas disciplinas, e a amostra pela quantidade de alunos que responderam o questionário.

A tabela a seguir apresenta a relação de disciplinas e a quantidade de alunos matriculados e que responderam o questionário.

Tabela 3: Disciplinas, população e amostra do estudo

\begin{tabular}{lcccc}
\hline Disciplina & $\begin{array}{c}\text { Total de alunos } \\
\text { matriculados }\end{array}$ & $\begin{array}{c}\text { Total de } \\
\text { respondentes do } \\
\text { questionário }\end{array}$ & $\begin{array}{c}\text { \% Total de alunos/ } \\
\text { Total de } \\
\text { respondentes }\end{array}$ \\
\hline Contabilidade de & 21 & 19 & $90 \%$ \\
Custos & 29 & 21 & $72 \%$ \\
Análise de Custos & $\mathbf{5 0}$ & $\mathbf{4 0}$ & $\mathbf{8 0 \%}$ \\
\hline Total & &
\end{tabular}

Fonte: Secretaria Acadêmica UCB (2010).

\subsection{Instrumento de pesquisa}


Uso do YouTube no ensino da contabilidade de custos: investigação empírica com alunos do Curso de

Ciências Contábeis da Universidade Católica de Brasília

Kelly Cristina de Carvalho Almeida, Karla Caroline Afiune Simões, Idalberto José das Neves Júnior

A elaboração do instrumento de pesquisa (questionário) foi fundamentada nos seguintes autores: Moran (1995), Toffolli (2007), Vargas et al., (2007) e Amaral et al., (2006). Este é composto por duas partes: a parte "A" que apresenta o perfil dos respondentes, e a "B" onde se procura verificar a opinião dos alunos em relação à utilização e contribuição de vídeos para o ensino de disciplinas da área de custos.

Foi aplicado um pré-teste durante a primeira semana do mês de novembro de 2009 em seis alunos que estavam cursando entre o $5^{\circ}$ e $8^{\circ}$ semestre da UCB, com o objetivo de identificar possíveis dificuldades de entendimento e obter melhorias. Após avaliar as sugestões, entendeu-se pertinente desmembrar a questão três em três perguntas.

\subsection{Protocolo de pesquisa}

A figura a seguir resume o processo de pesquisa realizado, contendo a fundamentação teórica, os procedimentos utilizados para a coleta de dados e os resultados.

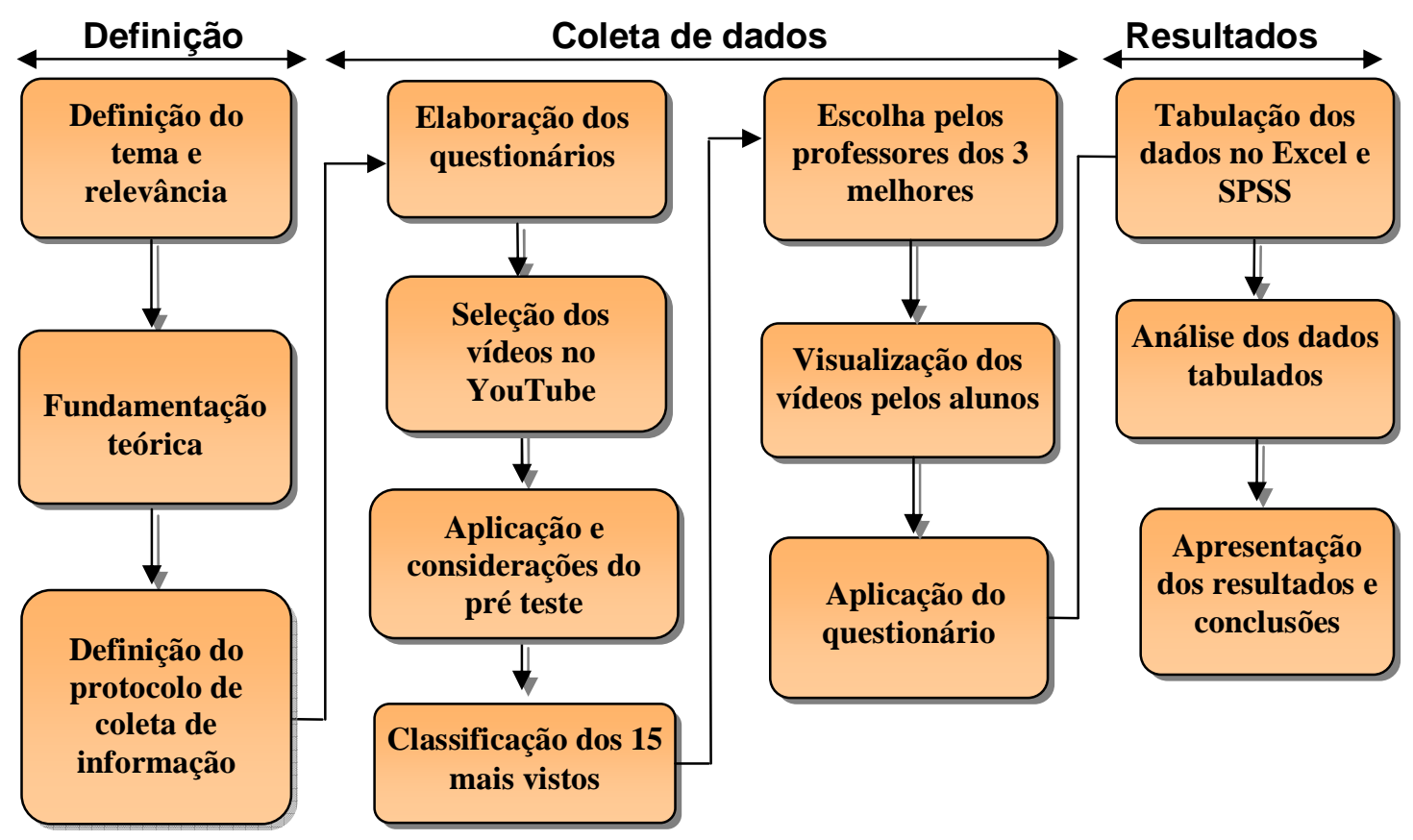

Fonte: Adaptado de Yin (1989).

Figura 1: Protocolo de pesquisa 
Uso do YouTube no ensino da contabilidade de custos: investigação empírica com alunos do Curso de

Ciências Contábeis da Universidade Católica de Brasília Kelly Cristina de Carvalho Almeida, Karla Caroline Afiune Simões, Idalberto José das Neves Júnior

\section{Análise dos resultados da pesquisa}

Após a aplicação do questionário aos alunos das disciplinas de contabilidade de custos e análise de custos, os dados foram tabulados no Excel e para obtenção dos resultados utilizou-se o Software estatístico Statistical Package for the Social Sciences (SPSS). Para melhor estruturação do resultado da pesquisa têm-se as seguintes subseções.

\subsection{Caracterização dos respondentes e professores}

Inicialmente, foram identificados dois profissionais especialistas na área de custos do curso de Ciências Contábeis. Em seguida, foi apresentado a eles os 15 vídeos mais vistos do YouTube para que ambos escolhessem os três melhores a serem apresentados em sala de aula. Destes, foi escolhido apenas um de cada disciplina para apresentar aos alunos em sala 
Uso do YouTube no ensino da contabilidade de custos: investigação empírica com alunos do Curso de

Ciências Contábeis da Universidade Católica de Brasília

Kelly Cristina de Carvalho Almeida, Karla Caroline Afiune Simões, Idalberto José das Neves Júnior

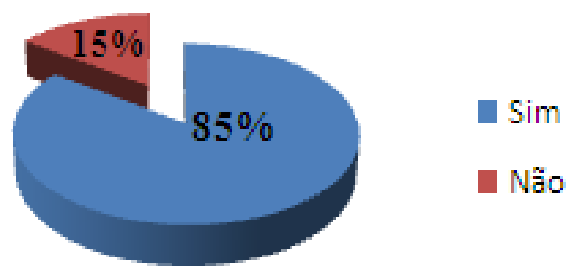

Gráfico 1: Consistência no conteúdo

Na segunda pergunta procurou-se medir o grau de conhecimento do aluno em relação à produção de vídeos, onde $5 \%$ afirmam ter um conhecimento excelente, $10 \%$ muito bom, $42,5 \%$ disseram que tem um bom conhecimento, 35\% qualificam como médio e 7,5\% consideram ruim seu conhecimento (Gráfico 2).

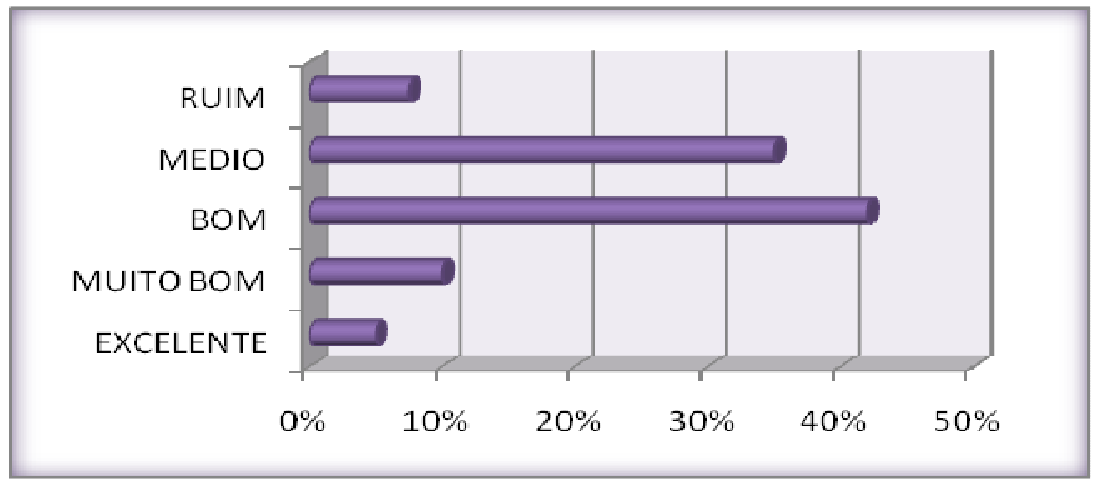

Gráfico 2: Grau de conhecimento

O conhecimento sobre a produção de vídeos torna-se um diferencial, pois o indivíduo adquire uma visão crítica e autônoma buscando vídeos com maior qualidade e tendo mais proveito para com o objetivo educacional (VARGAS, 2007).

Com base na pergunta anterior, pediu-se a opinião dos alunos quanto ao áudio, imagem e conteúdo apresentado no vídeo exibido em sala de aula. Em relação ao áudio, 50\% dos alunos avaliaram como bom, sendo que o mesmo conceito foi atribuído por $52.5 \%$ dos alunos à imagem, e 47,5\% ao conteúdo (Gráfico 3). 
Uso do YouTube no ensino da contabilidade de custos: investigação empírica com alunos do Curso de

Ciências Contábeis da Universidade Católica de Brasília

Kelly Cristina de Carvalho Almeida, Karla Caroline Afiune Simões, Idalberto José das Neves Júnior

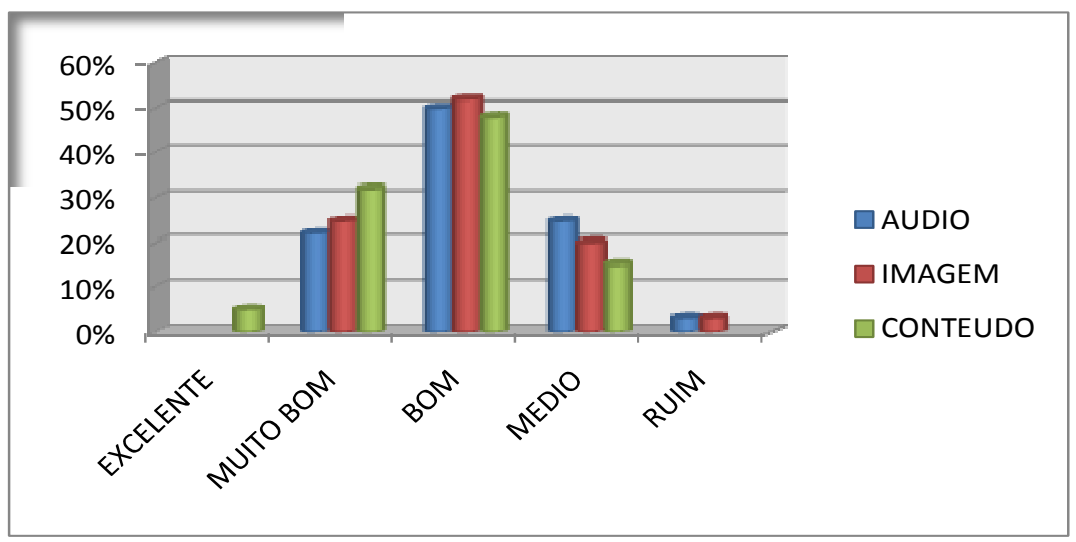

Gráfico 3: Qualidade do vídeo

$\mathrm{Na}$ quinta questão, 32\% dos alunos afirmam que há incentivo por parte do corpo de professores da UCB do curso de contabilidade em utilizar as mídias educacionais modernas como, por exemplo, a Internet e vídeo para auxiliar na formação acadêmica. Apesar de vários professores adotarem essas mídias, ainda há receio por parte deles em aceitá-las, muitas vezes devido a conceitos pré-concebidos a respeito da Internet a da cultura do mesmo (TOFFOLLI, 2007). Os resultados estão expressos no Gráfico 4.

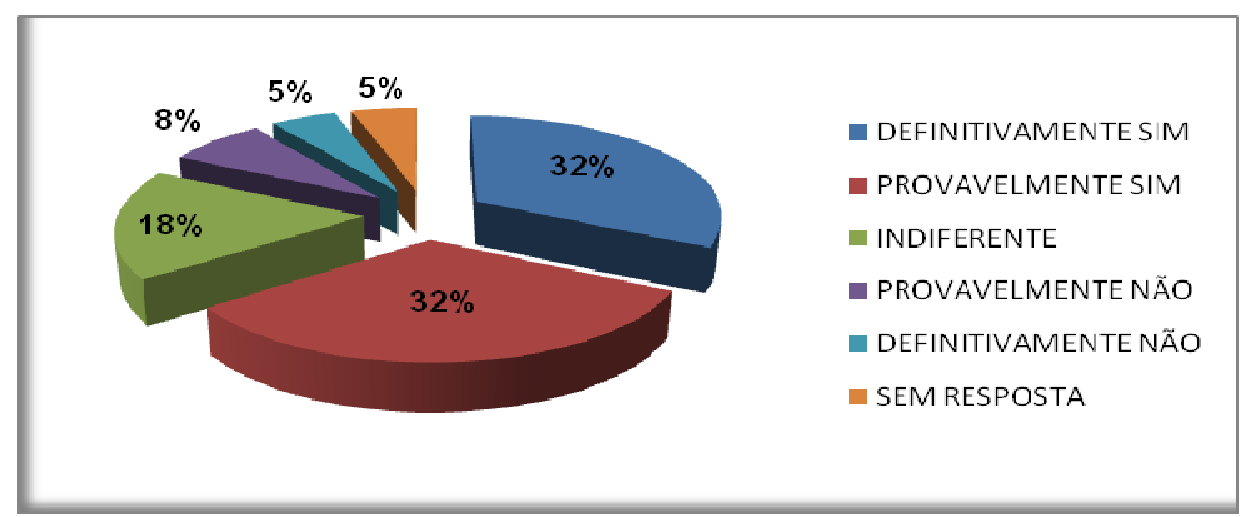

Gráfico 4: Incentivo do corpo docente

Nas respostas à sexta pergunta, constatou-se que $53 \%$ dos respondentes crêem que esses vídeos contribuem para a compreensão da contabilidade, para aqueles sem conhecimento acadêmico (Gráfico 5). 
Uso do YouTube no ensino da contabilidade de custos: investigação empírica com alunos do Curso de

Ciências Contábeis da Universidade Católica de Brasília Kelly Cristina de Carvalho Almeida, Karla Caroline Afiune Simões, Idalberto José das Neves Júnior

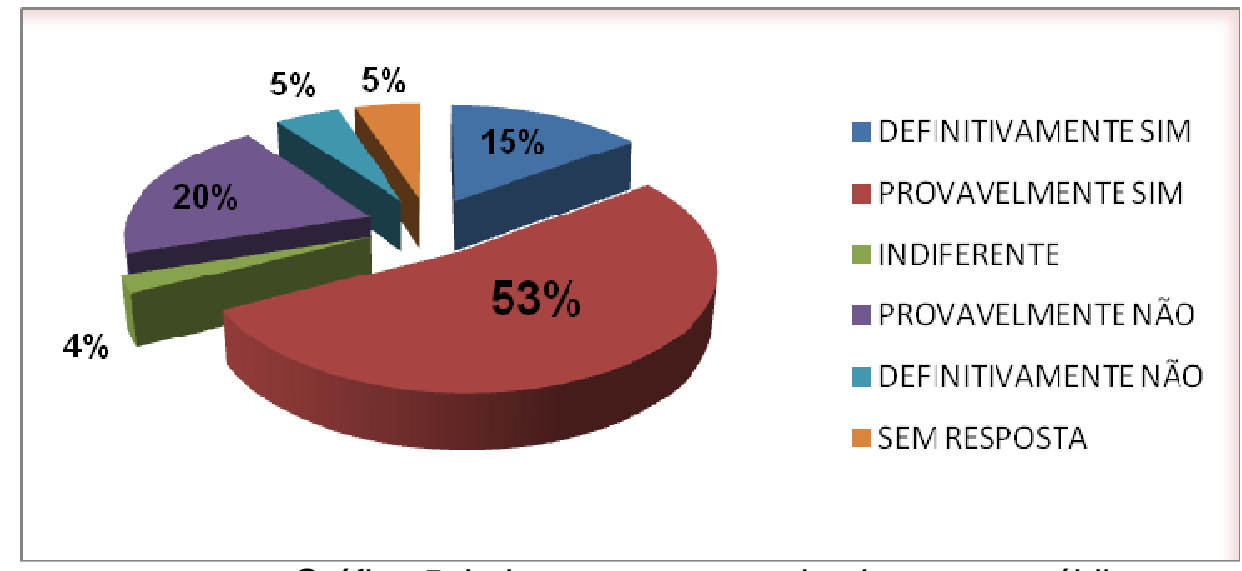

Gráfico 5: Leigo quanto ao conhecimento contábil

A sétima pergunta questionou a respeito da utilização do site como instrumento facilitador do aprendizado no decorrer da formação acadêmica, tendo $47 \%$ afirmado acessar com tal finalidade, $48 \%$ não o faz e $5 \%$ não souberam ou quiseram responder. Pela quantidade de alunos que informa acessar a Internet, pode-se concluir acerca da propensão cada vez maior do uso de vídeos por parte dos alunos (Gráfico 6).

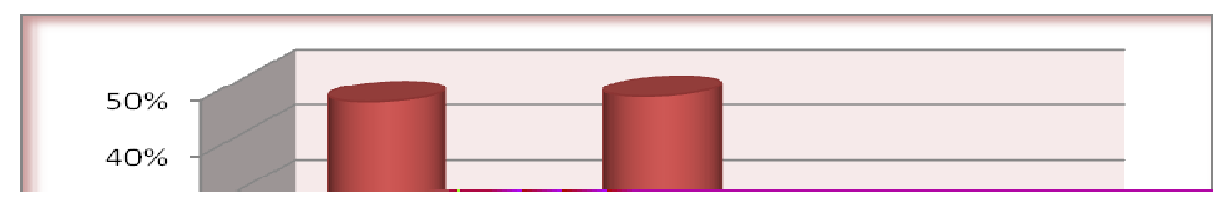


Uso do YouTube no ensino da contabilidade de custos: investigação empírica com alunos do Curso de

Ciências Contábeis da Universidade Católica de Brasília

Kelly Cristina de Carvalho Almeida, Karla Caroline Afiune Simões, Idalberto José das Neves Júnior

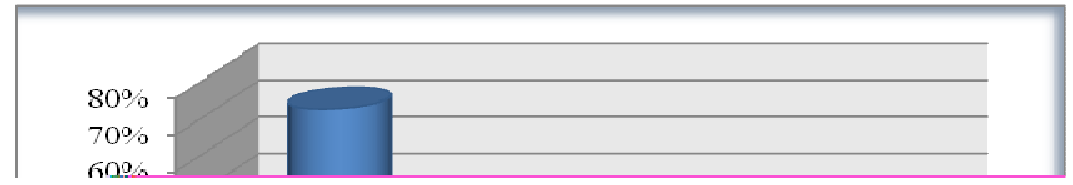


Uso do YouTube no ensino da contabilidade de custos: investigação empírica com alunos do Curso de

Ciências Contábeis da Universidade Católica de Brasília

Kelly Cristina de Carvalho Almeida, Karla Caroline Afiune Simões, Idalberto José das Neves Júnior

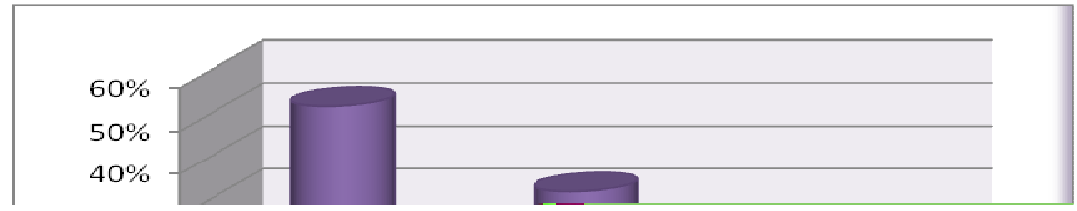


Uso do YouTube no ensino da contabilidade de custos: investigação empírica com alunos do Curso de

Ciências Contábeis da Universidade Católica de Brasília

Kelly Cristina de Carvalho Almeida, Karla Caroline Afiune Simões, Idalberto José das Neves Júnior

Interesse de produzir e divulgar o vídeo Sim

$57,1 \%$ Não

$84,6 \%$

Legenda: C.C = Contabilidade de Custos; A.C = Análise de Custo; D. Sim = Definitivamente sim; P. Sim = Provalvelmente sim.

A partir dos dados apresentados, observam-se informações semelhantes e diferentes nos dois clusters. Em ambos, nota-se um perfil predominantemente jovem, sendo diferenciados por gênero e disciplina. No cluster 1 observa-se que $55 \%$ dos alunos pertencem ao sexo masculino e estão matriculados na disciplina de contabilidade de custos, enquanto o cluster 2 é basicamente formado pelo sexo feminino e disciplina de análise de custos.

Com relação à utilização do site no auxilio da formação acadêmica, foi identificada uma particularidade quanto ao sexo, pois $52,6 \%$ do gênero masculino acessam-no com finalidade educacional e tem interesse em produzir e divulgar um vídeo, diferentemente das mulheres que não acessam o site e não possuem interesse em produzir e divulgá-los.

Após a comparação dos dois clusters, pode-se afirmar que em grande maioria há semelhança entre as respostas.

\section{Considerações Finais}

$\mathrm{Na}$ pesquisa realizada verificou-se a utilização de vídeos postados no Youtube e confirmou-se a contribuição para o ensino, considerando os principais aspectos dos resultados como a produção de vídeos e o conteúdo apresentado através da opinião dos alunos das disciplinas de Contabilidade de Custos e Análise de Custos do curso de Ciências Contábeis da Universidade Católica de Brasília. Em suma, os resultados demonstraram que 45\% dos alunos apresentam um bom conhecimento em produção de vídeos, avaliando qualitativamente como eficiente os vídeos postados no site quanto ao conteúdo, áudio e imagem.

Os mesmos afirmam que $32 \%$ dos professores do curso de ciências contábeis da UCB incentivam a utilização desta ferramenta como auxilio na formação acadêmica, com isso $47 \%$ dos alunos utilizam o site, todavia $88 \%$ responderam nunca ter produzido qualquer vídeo, embora $52 \%$ têm interesse em produzi-los e divulgá-los.

Constatou-se, ainda, que $53 \%$ dos respondentes concordam sobre a contribuição destes vídeos para o aprendizado de pessoas leigas no assunto e, por conseguinte, que o site pode ser utilizado como um instrumento de ensino.

Ao serem analisadas as três questões subjetivas, das afirmações feitas foi concluído que poderia haver aperfeiçoamento dos vídeos assistidos quanto ao áudio, à imagem, a 
Uso do YouTube no ensino da contabilidade de custos: investigação empírica com alunos do Curso de

Ciências Contábeis da Universidade Católica de Brasília

Kelly Cristina de Carvalho Almeida, Karla Caroline Afiune Simões, Idalberto José das Neves Júnior

iluminação e vocabulário, respectivamente. Muitos reforçaram que apesar de considerar os vídeos como um instrumento de estudo, estes não substituem de nenhuma forma a aula presencial e as tradicionais metodologias de ensino.

Como existem lacunas na literatura quanto à abordagem de opinião dos autores dos vídeos postados no site Youtube, considera-se que o tema é relevante para todos os usuários identificados com novas possibilidades educacionais. Outra perspectiva neste mesmo contexto seria propor melhoria para estes vídeos, para consolidá-los como metodologia de ensino nas faculdades e universidades de todo o país.

\section{Referências}

AMARAL et al (2006). Desenvolvimento de um Ambiente Midiatizado para uso de vídeos interativos na educação. Disponível em: http://ihm.ccadet.unam.mx/virtualeduca2006/pdf/88SA.pdf. Acesso em: 06 set. 2009.

ANJOS, G. C. B. dos; CASTRO, W. A. M. A utilização da internet pelos cursos de graduação em Administração: um estudo nos sites das IFES brasileiras. Disponível em: http://www.aedb.br/seget/artigos07/1288_1288_Internet_IFES_Seget_final.pdf. Acesso em: 20 jan 2010.

BOGO, Kellen Cristina. A História da Internet: Como Tudo Começou... Disponível em: http://kplus.cosmo.com.br/materia.asp?co=11\&rv=Vivencia. Acesso em: 09 set. 2009.

CRUZ, Dulce Márcia, BRUN, Roseli Maria (2002). A internet com ferramenta de apoio ao processo de ensino e aprendizagem no ensino superior. Disponível em: http://200.169.53.89/download/CD\%20congressos/2002/2\%20CBComp/html/artigos/informatica\%2 Ona\%20educacao/ine003.pdf. Acesso em: 05 fev. 2010.

FALKEMBECH, Gilse Antoninha Morgental (2005). Concepção e desenvolvimento de material educativo digital. Disponível em:

http://www.cinted.ufrgs.br/renote/maio2005/artigos/a23_materialeducativo.pdf. Acesso em: 06 set. 2009.

G1. Conheça a história do site de vídeos YouTube. Disponível em:

http://g1.globo.com/Noticias/Tecnologia/0, AA1306288-6174,00.html. Acesso em: 09 set.2009.

KRAEMER, Maria Elisabeth. E-learning na contabilidade. Brasília: Revista Brasileira de Contabilidade, no 144, Nov-Dez 2003.

MARTINS, Eliseu. Contabilidade de custos. 9a Edição. São Paulo: Atlas, 2003.

MORAN, José Manuel (2009a). O vídeo na sala de aula. Disponível em:

<http://www.eca.usp.br/prof/moran/ vidsal.htm>. Acesso em: 06 set. 2009.

MORAN, José Manuel (2009b) O que é educação à distância. Disponível em:

http://www.eca.usp.br/prof/moran/dist.htm. Acesso em: 08 set. 2009. 
Uso do YouTube no ensino da contabilidade de custos: investigação empírica com alunos do Curso de

Ciências Contábeis da Universidade Católica de Brasília

Kelly Cristina de Carvalho Almeida, Karla Caroline Afiune Simões, Idalberto José das Neves Júnior

NEVES JÚNIOR, Idalberto José; MEDEIROS, Thaís Alves; BATISTA, Cristiane de Paula.

Aprendizagem cooperativa e tecnológica educacional na disciplina de contabilidade geral II do curso de ciências contábeis da Universidade Católica de Brasília - Em estilo salesiano de educar. In:. XXX Encontro da ANPAD. Anais... XXX EnANPAD, Salvador, 2006.

NEVES JÚNIOR, Idalberto José; MENDES, Hugo. Metodologias de ensino em contabilidade: uma análise sob a ótica dos estilos de aprendizagem. In: XXXIV Encontro da ANPAD. Anais... XXX EnANPAD, Rio de Janeiro, 2010.

NOSSA, Valcemiro. Formação do corpo docente dos cursos de graduação em contabilidade no Brasil: uma análise crítica. Caderno de estudos da FIPECAFI, São Paulo, mai-ago. 1999

RAUPP, Fabiano M.; AMBONI, Nério; CUNHA, Daniela Regina; DUARTE, Juliana Fraga; AGOSTINETO, Raquel Crestane (2009). O ensino de contabilidade de custos nos cursos de graduação em administração do Estado de Santa Catarina. Disponível em:

http://www.unisinos.br/abcustos/_pdf/148.pdf. Acesso em: 16 mar. 2010.

SCARPIN, J. E; GRANDE, J. F. (2007). O ensino da Contabilidade de custos voltado às empresas prestadoras de serviços nos cursos de Ciências Contábeis de Santa Catarina. Disponível em:http://www.abcustos.org.br/texto/viewpublic?ID_TEXTO=2569. Acesso em: 08 abr. 2010.

TOFFOLLI, Tânia Luiza da Silva. Internet utilizada como tecnologia de apoio entre professor e aluno no ensino superior. Disponível em: http://www2.dc.uel.br/nourau/document/?view=469. Acesso em: 24 mar. 2010.

VARGAS, A.; ROCHA, H. V.; FREIRE, F. M. Promídia: produção de vídeos digitais no contexto educacional. Disponível em: http://www.cinted.ufrgs.br/ciclo10/artigos/1bAriel.pdf. Acesso em: 06 set. 2009.

VERGARA, Sylvia Constant. Projetos e relatórios de pesquisa em administração. São Paulo: Atlas, 2000. 